\title{
GMR
}

\section{Cloning and expression pattern analysis of BkGRAS2 from Betula kirghisorum}

\author{
G.Y. Li ${ }^{1}$, C.J. Yang ${ }^{1}$ and G.J. Liu $^{2}$ \\ ${ }^{1}$ College of Forestry, Northeast Forestry University, Harbin, China \\ ${ }^{2}$ State Key Laboratory of Tree Genetics and Breeding, \\ Northeast Forestry University, Harbin, China \\ Corresponding author: C.J. Yang \\ E-mail:nxyycj@sina.cn \\ Genet. Mol. Res. 14 (3): 11335-11347 (2015) \\ Received April 9, 2015 \\ Accepted July 14, 2015 \\ Published September 22, 2015 \\ DOI http://dx.doi.org/10.4238/2015.September.22.27
}

ABSTRACT. GRAS proteins are plant-specific transcription factors that are involved in the regulation of root and shoot growth. Here, we cloned BkGRAS2 from Betula kirghisorum (abbreviated to $\mathrm{Bk}$ ) and analyzed the physicochemical properties and expression pattern of the encoded protein. BkGRAS2 had an open reading frame of 1614 bp encoding 537 amino acid residues. The deduced BkGRAS2 protein was hydrophilic, and it contained highly conserved VHIID and SAW motifs. BkGRAS1 and BkGRAS2 showed considerable sequence similarities. An expression analysis indicated that BkGRAS2 was expressed in root, stem, and leaf, with the highest level in the leaf. Expression of BkGRAS2 was increased following stress treatment with $0.6 \% \mathrm{NaHCO}_{3}$. Transient expression analysis of GFP-BkGRAS2 in onion epidermal cells revealed that the BkGRAS2 protein was localized in the cytoplasm, but could also be detected in the nucleus. Our study provides the basis for future research on the role of the GRAS gene family in B. kirghisorum.

Key words: Betula kirghisorum; GRAS transcription factor; Expression pattern; $\mathrm{NaHCO}_{3}$ stress; Subcellular localization 


\section{INTRODUCTION}

Soil salinization as a result of natural factors and human industrial and agricultural activities is an increasingly serious ecological problem worldwide. In particular, soil salinization restricts the development of agriculture and the forestry industry and requires ecosystem restoration. In China, it is estimated that about $3.69 \times 10^{7} \mathrm{hm}^{2}$ of arable land is affected by soil salinization, i.e., approximately one-quarter of the available land, and that this area is increasing annually (Foyer and Noctor, 2000; Tester and Davenport, 2003). In addition to soils affected by human activities, there are areas with naturally high levels of soil salinity. For example, the Songnen Plain of the northeast region of China is one of the three largest areas of soda saline soil in the world (Pan et al., 2006). The physicochemical property analysis of saline soil indicated that $\mathrm{pH}$ was between 9.6 and 10.2 in this area, showing a strong base reaction (Wang et al., 2001).

Over the last two decades, considerable research effort has been devoted to investigation of the GRAS gene family, which encode plant specific transcription factors. The proteins have a conserved C-terminal domain and a highly variable $\mathrm{N}$-terminal domain. The family has been divided into eight subfamilies, namely, DELLA, HAM, LISCL, PAT1, LS, SCR, SHR, and SCL3 (Tian et al., 2004). These transcription factors play an important role in the growth and development of plants (Schumacher et al., 1999; Llave et al., 2002; Stuurman et al., 2002; Gao et al., 2004; Sánchez et al., 2007), GA signal transduction (Peng and Harberd, 1997; Silverstone et al., 1997; Lee et al., 2002; Wen and Chang, 2002), light signal transduction (Bolle et al., 2000; Torres-Galea et al., 2006, 2013), and other biotic and abiotic stress processes. For example, in Arabidopsis, SCARECROW-LIKE 3 (SCL3) acts as a positive regulator to integrate and maintain a functional GA pathway by attenuating DELLA repressors in the Arabidopsis root, enabling root cell elongation and shoot tissue maturation (Heo et al., 2011; Zhang et al., 2011).

Our laboratory is interested in elucidating the salt tolerance mechanism in Betula kirghisorum, with the ultimate aim of cultivating salt tolerant varieties. Such varieties could be applied to the improvement of the saline alkali soils of the Northeast region of China, and improve the habitat for rare plants and overcome the low species diversity in these saline and alkaline areas. Unfortunately, little attention has been paid to GRAS genes in B. kirghisorum, although we did successfully clone a GRAS gene, BkGRAS1 (Yang et al., 2013). In the present study, we have extended our studies of this species and successfully cloned a second GRAS gene, BkGRAS2. We investigated salt resistance of different organizations of Betula kirghisorum and examined BkGRAS2 expression under salt stress conditions. The study has potentially important practical significance for soil improvement and environmental greening of the saline and alkaline areas of the Northeast region of China.

\section{MATERIAL AND METHODS}

\section{Plant materials}

One-year-old $B$. kirghisorum plants were obtained from the breeding garden of the Northeast Forestry University. Similar-sized plants (20-30 cm tall) with 15-20 leaves were used for the expression analysis. The plants were subjected to stress for different lengths of time, namely, $0,12,24$ or $48 \mathrm{~h}$; the stress was applied by watering the plants with $0.6 \% \mathrm{NaHCO}_{3}$. 


\section{Reagents and vector}

DNA digestive enzymes, reverse transcription reagents, Ex Taq, and OMEGA gel extraction kit were purchased from TaKaRa Biotechnology (Dalian) Co., Ltd. The plasmid extraction kit and $\mathrm{DH} 5 \mathrm{a}$ competent cells were purchased from Tiangen Biotech Ltd. All reagents were of analytical grade. For cloning, we used the $p M D 18-T$ vector; for expression analysis, we used the $p B / 121$ GFP vector

\section{Isolation of BkGRAS2}

Primers of BkGRAS2 clone were designed according to the sequence from the Betula kirghisorum transcriptome sequencing. Total RNA was extracted by the CTAB method from leaves of unstressed $B$. kirghisorum plants and subjected to agarose gel electrophoresis. cDNA synthesis was performed using M-MLV reverse transcriptase and an oligo(dT) primer. The cDNA sequence was amplified by PCR using the primers shown in Table 1.

Table 1. Primers used to clone BkGRAS2.

\begin{tabular}{ll}
\hline Primer & Primer sequence $\left(5^{\prime} \rightarrow 3^{\prime}\right)$ \\
\hline BkGRAS2-F & ATTCTCCCCTTTGTTTCTTGGCTAA \\
BkGRAS2- $R$ & CAGAGCAACCATTTTCACCTCCAAG \\
\hline
\end{tabular}

\section{Bioinformatic and structural domain analysis of BkGRAS2}

The physicochemical properties of the protein encoded by BkGRAS2 were predicted using the online Expasy Protparam (http://web.expasy.org/protparam/). The gene domains were predicted using CDD online software (http://www.ncbi.nlm.nih.gov/Structure/cdd/wrpsb.cgi). The structural motifs of BkGRAS2 were determined using the published information on GRAS family domains in Arabidopsis thaliana (Pysh et al., 1999).

\section{Comparison of BkGRAS1 and BkGRAS2 at the nucleotide and protein levels}

The nucleotide blast software (http://blast.ncbi.nlm.nih.gov/Blast.cgi?PROGRAM= blastn\&PAGE_TYPE=BlastSearch\&LINK_LOC=blasthome) in NCBI was used to analyze differences between BKGRAS1 and BKGRAS2 nucleotide sequences. The relationship between BkGRAS1 and BkGRAS2 proteins were analyzed using the ClustalW2 software (http://www.ebi. ac.uk/Tools/msa/clustalw2/).

\section{PCR analyses}

Total RNAs from roots, stems, and leaves of $B$. kirghisorum were obtained by the CTAB method from tissues sampled after different periods of stress. Each RNA sample was treated with DNasel and used to produce cDNA. The cDNA was diluted 5-fold and used as the template for PCR amplification with the primers shown in Table 2. The PCR products were separated on a $1.0 \%$ agarose gel and stained with ethidium bromide. Quantitative real-time PCR (qRT-PCR) assay was 
performed using the same RNA samples and primer sets. The Betula $18 \mathrm{~S}$ transcript was used as a control, and the relative levels of BkGRAS2 in each sample were normalized against 18S transcript levels. SYBR green was used to monitor the kinetics of PCR product formation in qRT-PCR; each PCR assay was carried out three times. The qRT-PCR reaction conditions are outlined in Table 3, and 40 PCR cycles were performed: $94^{\circ} \mathrm{C}$ for $5 \mathrm{~s}, 60^{\circ} \mathrm{C}$ for $34 \mathrm{~s}$. The relative quantification value of BkGRAS2 was calculated by the $2^{-\Delta \Delta \mathrm{Ct}}$ method and the results from one representative experiment are shown.

Table 2. Quantitative Real-time PCR Primers for BkGRAS2.

\begin{tabular}{ll}
\hline Primer & Primer sequence $\left(5^{\prime} \rightarrow 3^{\prime}\right)$ \\
\hline $18 S-F$ & ATCTTGGGTTGGGCAGATCG \\
$18 S-R$ & CATTACTC CGATCCCGAAGG \\
BkGRAS2-F & AGGCACT GGCTCAAGGAA \\
BkGRAS2-R & TGTAA GCACCCAATCGTT \\
\hline
\end{tabular}

Table 3. Reaction mixture for quantitative real-time PCR of BkGRAS2.

\begin{tabular}{lc}
\hline Component & Volume \\
\hline 2X TransStart ${ }^{\circledast 1 p}$ Green qPCR SuperMix & $10 \mu \mathrm{L}$ \\
Passive Reference Dye $(50 \mathrm{X})$ & $0.4 \mu \mathrm{L}$ \\
Forward Primer $(10 \mu \mathrm{M})$ & $0.4 \mu \mathrm{L}$ \\
Reverse Primer $(10 \mu \mathrm{M})$ & $0.4 \mu \mathrm{L}$ \\
cDNA $(5 \mathrm{X})$ & $2.0 \mu \mathrm{L}$ \\
$\mathrm{ddH}_{2} \mathrm{O}$ & up to $20 \mu \mathrm{L}$ \\
\hline
\end{tabular}

\section{Subcellular localization analysis}

For the analysis of the subcellular distribution of the BkGRAS2 protein, the coding region of BkGRAS2 (without the termination codon) was inserted upstream of the GFP element of the pB/121-GFP vector. The fusion construct (35S-BkGRAS2-GFP), under the control of the cauliflower mosaic virus (CaMV) 35S promoter, was introduced into onion epidermal cells by the particle bombardment method using the PDS-1000 System (BioRad) at 1350 psi helium pressure. A blank 35S-GFP vector was used as a control. Onion cells were cultured for $24 \mathrm{~h}$ in the dark in a Tissue Culture room (Beijing Kingpeng Internatioal Hi-Tech Corporation) and then analyzed using a fluorescence microscope.

\section{RESULTS AND DISCUSSION}

\section{Isolation of BkGRAS2}

The GRAS gene family is widely distributed in plants. Currently, 33 GRAS transcription factors have been identified in Arabidopsis thaliana, mainly from the SCL (Pysh et al., 1999), GAI (Peng et al., 1997), RGA (Silverstone et al., 1998), and SCR sub-families (Laurenzio et al., 1996). Sixty GRAS family members are known in rice, such as MOC1 (Li et al., 2003), SLR1 (Ikeda et al., 2001), and CIGR1/2 (Day et al., 2004). GRAS genes have been also isolated from maize (Lim et al., 2000), Pinus (Solé et al., 2008), Medicago truncatula (Kim and Nam, 2013). 
RNA electrophoresis detection is shown in Figure 1. cDNA synthesis was performed using M-MLV Reverse Transcriptase and an Oligo(dT) primer. We designed clone primers in the $5^{\prime}$ and $3^{\prime}$ untranslated regions of BkGRAS2. The cDNA sequence was amplified by PCR using the primers (Table1). Sequencing after genetic transformation, we obtained the band of 1675 bp (Figure 2), in which the CDS (Coding sequence) was $1614 \mathrm{bp}$. Sequencing results indicated that the gene did not contain any introns in its coding region (Figure 3 ).

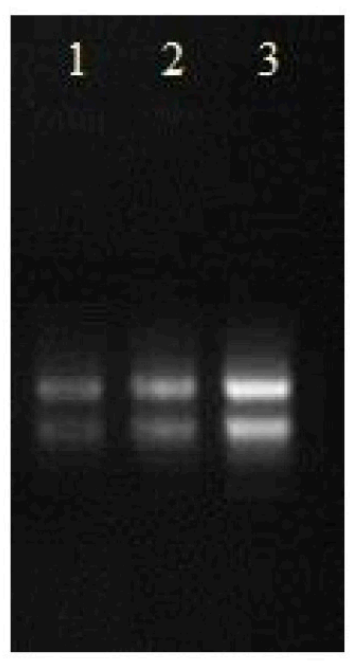

Figure 1. Electrophoretic detection of total RNA. After extraction from untreated (control) leaves (lanes 1, 2, and 3), RNA was detected on $1.0 \%$ agarose gels.

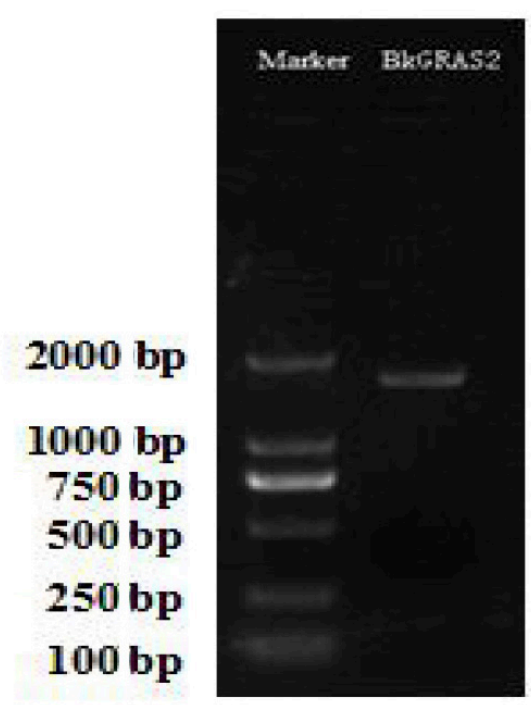

Figure 2. CDNA product of $B k G R A S 2$ produced by PCR amplification. The sequence was amplified using the primers BkGRAS2-F and BkGRAS2-R. Left lane: DM2000 size marker; right lane: BkGRAS2 gene product. 


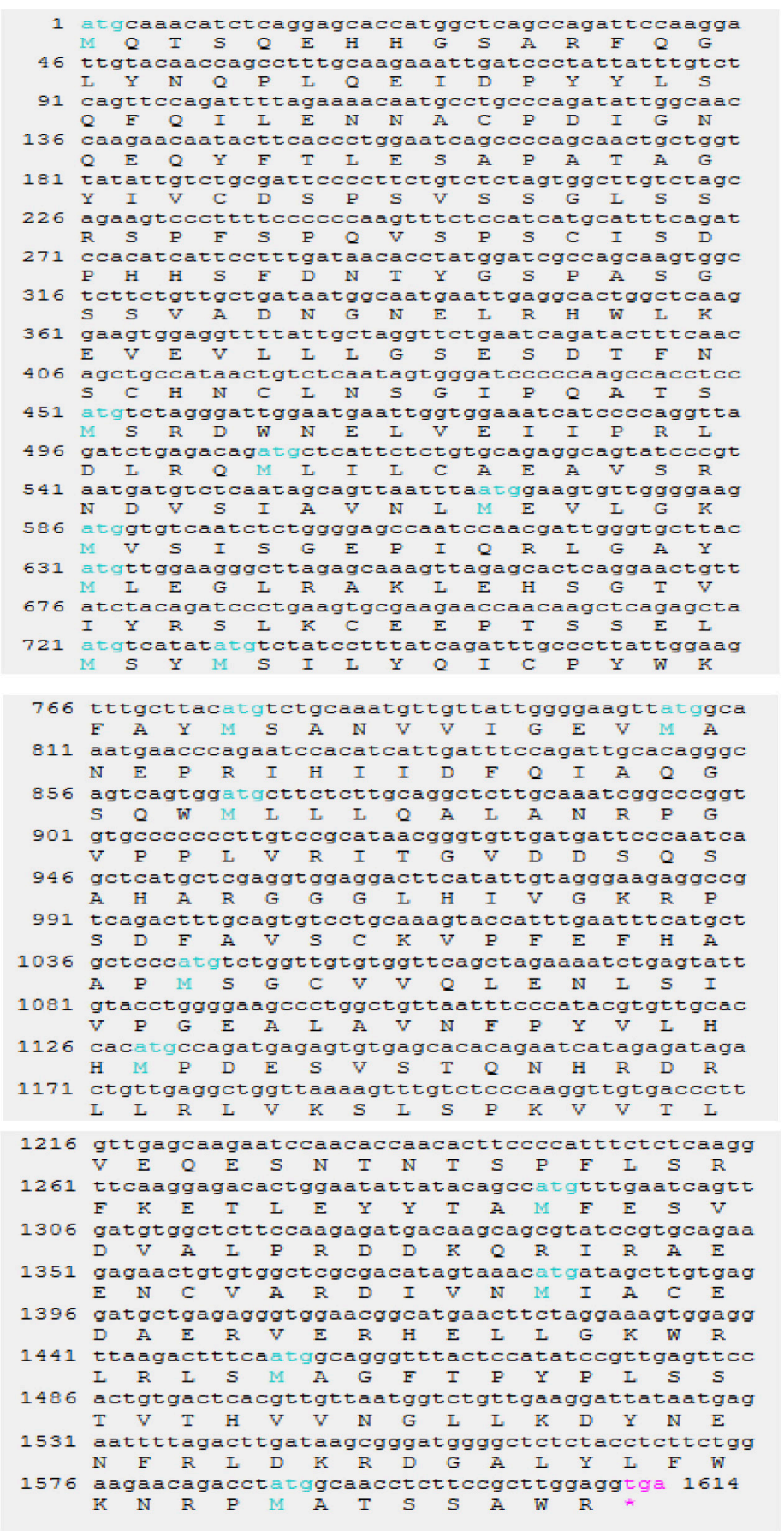

Figure 3. Analysis of the open reading frame of $B K G R A S 2$. The open reading frame of $B k G R A S 2$ was determined using the ORF finder procedure (http://www.ncbi.nlm.nih.gov/gorf/gorf.html) in NCBI. Codons marked in blue are initiation codon (first "atg") and nucleotides coding methionine (other "atg" codons). In pink, there is the termination codon. 


\section{Bioinformatics and structural domain analysis of BkGRAS2}

Previously, according to the results of transcriptome sequencing our laboratory cloned the first GRAS gene from Betula kirghisorum and named it BkGRAS1 (Yang et al., 2013). Nowadays, we cloned the second gene and use the NCBI CCD software to analyze the predicted protein of the isolated open reading frame which indicated that the gene belonged to the GRAS family (as shown in Figure 4). Therefore, we designated the gene as BkGRAS2. The open reading frame of BkGRAS2 is shown in Figure 3. It is predicted to encode a protein of 537 amino acid residues with an estimated molecular mass of $60.0 \mathrm{kDa}$ and a theoretical pl of 5.56 . The grand average of hydropathicity was -0.223 , indicating that the BkGRAS2 protein was hydrophilic.

Comparison of the deduced amino acid sequence of BkGRAS2 with $A$. thaliana GRAS proteins (Figure 5) indicates the presence of typical GRAS domains. For the VHIID motif, the P-NH-D-Q-L residues were absolutely conserved, whereas the SAW motif was characterized by three pairs of absolutely conserved residues, R-E, W-G and W-W (Figure 5).

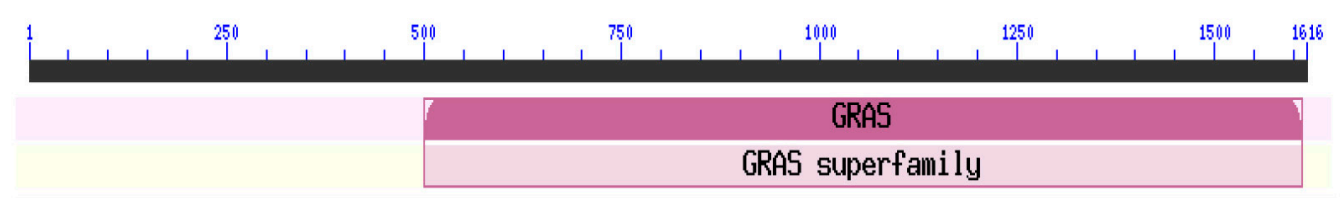

Figure 4. Schematic diagram of the BkGRAS2 domain. Prediction of the gene domains using the CDD software (http:// www.ncbi.nlm.nihgov/Structure/cdd/wrpsb.cgi).

\section{Comparison of BkGRAS1 and BkGRAS2 nucleotide and protein sequences}

A comparison of the open reading frames of BkGRAS1 (Yang et al., 2013) and BkGRAS2 showed they had equal lengths. Additionally, the two genes have many similarities in their physical and chemical properties. Therefore, we further characterized the relationship of the two genes at the nucleotide and protein levels using nucleotide blast and the ClustalW2 software (Figures 6 and 7). The nucleotide sequence comparison identified seven base pair changes in the two genes (Figure 6). The amino acid sequence comparison identified four different amino acids between BkGRAS1 and BkGRAS2 proteins (Figure 7). The differences between the two genes are summarized in Table 4.

\section{Effect of $0.6 \% \mathrm{NaHCO}_{3}$ stress on BkGRAS2 expression}

In the shoots and roots of Arabidopsis seedlings subjected to osmotic and drought stress, SCL13 expression was significantly increased (Guo et al., 2009). HcSCL13 expression is induced in Halostachys caspica by salt stress, suggesting that expression of this gene is related to salt tolerance (Zhou et al., 2013). The HcSCL13 protein has a transcriptional activation domain indicating that it is a transcription factor (Zhou et al., 2014). Ma et al. (2010, 2011) cloned the PeSCL7 gene from Populus euphratica and showed that its expression was induced by salt, drought stress treatment, and gibberellin (GA). Under salt stress conditions (350 mM NaCl), expression peaked after $3 \mathrm{~h}$ (Ma et al., 2011). 
$\begin{array}{ll}\text { AtSCL5 } & \text { ENYDLEMTDWLISQLQQMVSVSGEPVQRLGA YMLEGLVARLASSGSSIYKALRCKDPTGP } \\ \text { AtSCL21 } & \text { SENNLLMARWCMGELRGMVS ISGEP IQRLGA YMLEGLVARLAASGSS IYKSLQSREPESY } \\ \text { BkGRAS2 } & \text { SRNDVSIAVNLMEVLGKMVS ISGEP IQRLGA YMLEGLRAKLEHSGT IYRSLKCEEPTSS } \\ \text { AtSCL13 } & \text { ADGDFATAYGFLDVLEQMVSVSGSPIQRLGTYMAEGLRARLEGSGSNIYKSLKCNEPTGR } \\ & : \quad: \quad: \quad * * * * * * *: * * * * * * * * * *: * * *: * *: *: \ldots: \ldots\end{array}$

AtSCL5

AtSCL21

BkGRAS2

AtSCL13

AtSCL5

AtSCL21

BkGRAS2

AtSCL13

At SCL5

AtSCL21

BkGRAS2

AtSCL13

At SCL5

AtSCL21

BkGRAS2

AtSCL13

AtSCL5

AtSCL21

BkGRAS2

ELLTYMHILYEACPYFKFGYESANGAIAEAVKNESFVHI IDFQI SQGGQWVSLI RALGAR EFLSYVYVLHEVCPYFKFGYMSANGAIAEAMKDEERIHI IDFQI GQGSQW IALIQAFAAR ELMSYMS ILYQICPYWKFAYMSANVVIGEVMANEPRIHI IDFQI AQGSQWMLLLQALANR ELMSYMSVLYEICPYWKFAYTTANVEILEAI AGETRVHI IDFQI AQGSQYMFLI QELAKR $*::: *:: *:: * * *: * * . *: * * \quad * * .:$. $*: * * * * * * * . * * . *:: *::: . *$

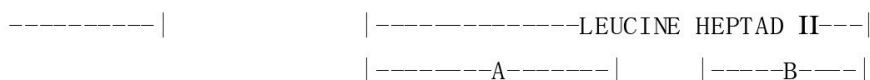

PGGPPNVRITGIDDPRSSFARQGGLELVGQRLGKLAEMCGVPFEFHGAALCCTEVEIEKL PGGAPNIRITGVGD--_- GSVLVTVKKRLEKLAKKFDVPFRFNAVSRPSCEVEVENL PGVPPLVRITGVDDSQSAHARGGGLHIVGKRPSDF AVSCKVPFEFHAAPMSGCVVQLENL PGGPPLLRVTGVDDSQSTYARGGGLSLVGERLATLAQSCGVPFEFHDA IMSGCKVQREHL

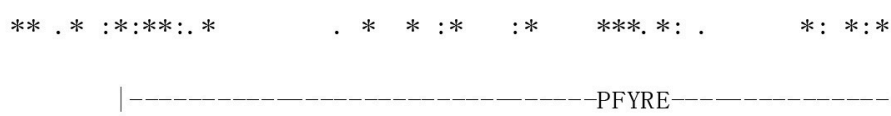

GVRNGEALAVNFPLVLHHMPDESVTVENHRDRLLRLVKHLSPNVVTLVEQEANTNTAPFL DVRDGEALGVNFAYMLHHLPDESVSMENHRDRLLRMVKSLSPKVVTLVEQECNTNTSPFL SIVPGEALAVNFPYVLHHMPDESVSTQNHRDRLLRLVKSLSPKVVTLVEQESNTNTSPFL GLEPGFAVVVNFPYVLHHMPDESVSVENHRDRLLHLIKSLSPKLVTLVEQESNTNTSPFL

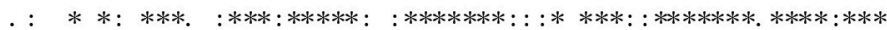

PRFVETMNHYLAVFESIDVKLARDHKERI NVEQHCLAREVVNLI ACEG VEREERHEPLGK PRFLETLSYYTAMFESIDVMLPRNHKERINIEQHCMARDVVNII ACEG AERIERHELLGK SRFKETLEYYTAMFESVDVALPRDDKQRI RAEENCVARD IVNMI ACEDAERVERHELLGK SRFVETLDYYTAMFESIDAARPRDDKQRI SAEQHCVARD IVNMI ACEESERVERHEVLG I .****:.:**:***:*. .*:.*:** *::*:**::**:**** *********

Figure 5. Alignment of the protein products of Arabidopsis GRAS genes and Betula kirghisorum BkGRAS2. The sequence alignment of the deduced amino acids identify highly conserved regions in BkGRAS2. The absolutely conserved residues within the VHIID, PFYRE, and SAW motifs are highlighted in bold red. Blue: in the A part of LEUCINE HEPTAD II motif, there were different amino acids between Betula kirghisorum and Arabidopsis. Underlined regions: in the literature (Pysh et al., 1999), some genes in Arapbidopsis did not contain PDES amino acids in this position. The BKGRAS2 gene was the same as AtSCL5, AtSCL13, and AtSCK21 genes, which contained PDES amino acids in this position. 


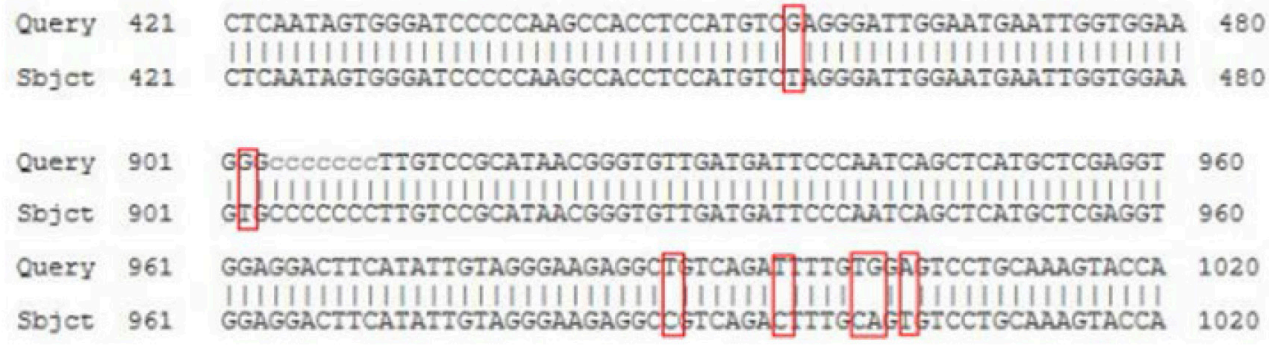

Figure 6. Comparison of the nucleotide sequences of BkGRAS1 and BkGRAS2 indicates seven base pair changes.

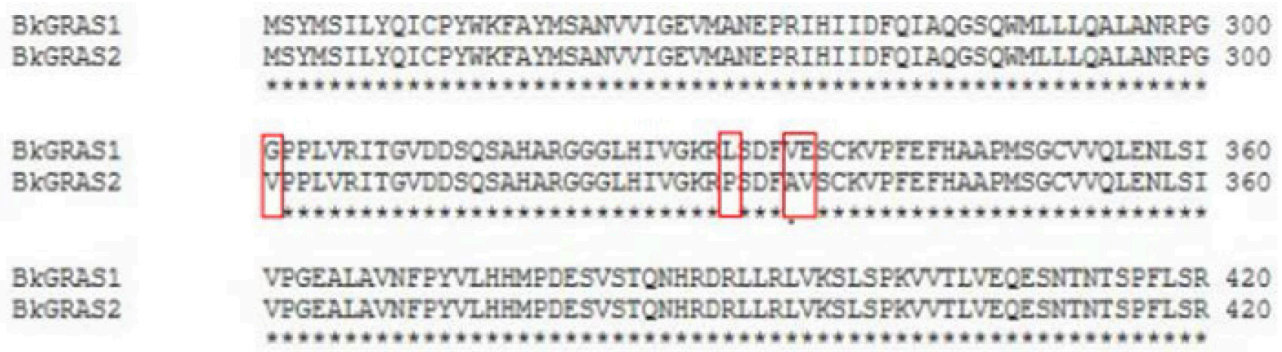

Figure 7. Comparison of amino acid sequences of BkGRAS1 and BkGRAS2 proteins. Four amino acids differences are present between the two proteins.

Table 4. Comparison of nucleotide and amino acid sequence differences between BkGRAS1 and BkGRAS2.

\begin{tabular}{|c|c|c|c|}
\hline Sequence number & Base change & Amino acid number & Amino acid change \\
\hline $454-456$ & TCG-TCI & & \\
\hline $901-903$ & GEG-GIG & 301 & G-V \\
\hline $988-990$ & $\mathrm{C} \overline{\mathrm{I}} \mathrm{G}-\mathrm{C} \overline{\mathrm{C}} \mathrm{G}$ & 330 & L-P \\
\hline $994-996$ & $\overline{G A} \bar{I}-G \bar{A} \underline{C}$ & & \\
\hline $1000-1002$ & GTG-GCA & 334 & V-A \\
\hline $1003-1005$ & $\overline{G A G-G \overline{I G}}$ & 335 & E-V \\
\hline
\end{tabular}

In the present study, a qRT-PCR assay showed that BkGRAS2 was expressed in all organs tested (roots, stems, and leaves) (Figure 8). Following exposure to stress $\left(0.6 \% \mathrm{NaHCO}_{3}\right)$ for different periods of time $(0,12,24$, and $48 \mathrm{~h})$ expression levels varied. In the untreated control, BkGRAS2 expression was highest in the leaf and lowest in the root (Figure 8A). Under stress conditions, BkGRAS2 expression rose rapidly in the root, with a peak at $12 \mathrm{~h}$ (Figure 8B). By contrast, expression levels in the stem did not immediately rise, but reached a maximum at $48 \mathrm{~h}$ (Figure 8C). Compared to the control, BkGRAS2 expression was greater in the leaves of treated plants at 12 and $48 \mathrm{~h}$, although it was low at $24 \mathrm{~h}$ (Figure 8D). The increased expression of $B k G R A S 2$ after $0.6 \% \mathrm{NaHCO}_{3}$ stress treatment suggested that the gene is involved in salt stress responses. 

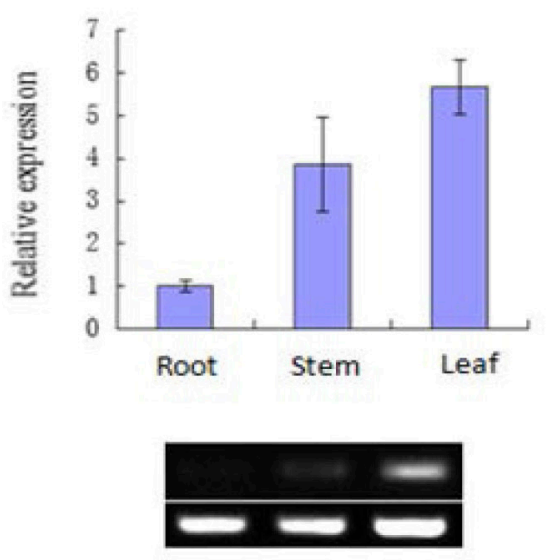

A $O \mathrm{~h}$
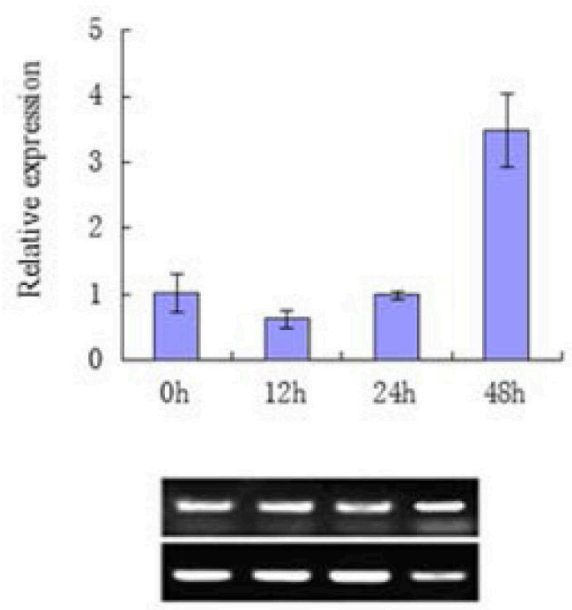

C Stem
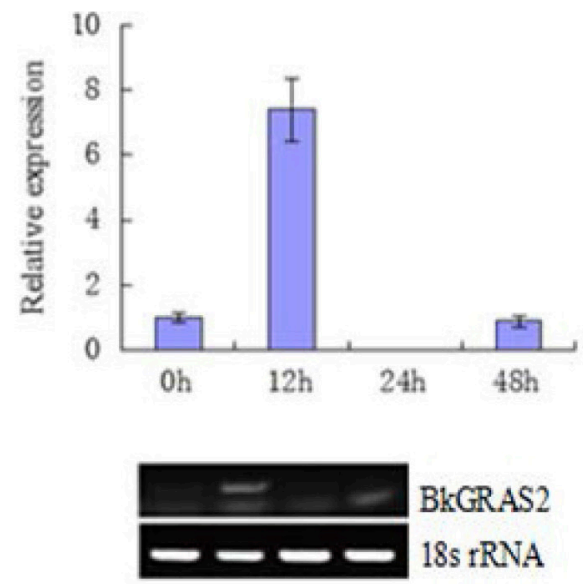

B Root
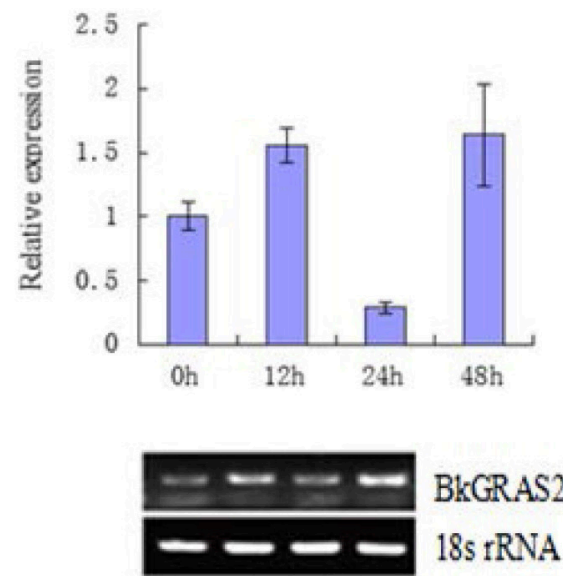

D Leaf

Figure 8. qRT-PCR and RT-PCR analyses of BkGRAS2 expression. (A) Level of BkGRAS2 transcripts under normal environmental conditions. The level of transcript in the root was set as 1.0. (B, C, D). Relative levels of expression in roots, stems, and leaves under $0.6 \% \mathrm{NaHCO}_{3}$ stress. Expression levels were normalized against $18 \mathrm{~S} \mathrm{rRNA}$, and the level of transcript in the controls $(0 \mathrm{~h}$, without stress) was set as 1.0 .

\section{Intracellular distribution of BkGRAS2}

The intracellular distributions of a few GRAS proteins have been reported. NtGRAS1 (Czikkel and Maxwell, 2007), RGA (Silverstone et al., 1998), and RGL (Wen and Chang, 2002) have been shown to localize to the nucleus, while PAT1 is mainly present in the cytosol (Bolle et al., 2000).

To study the intracellular distribution of BkGRAS2, the coding region of BkGRAS2 was fused to GFP under the control of a $35 \mathrm{~S}$ promoter. The fusion plasmid (35S-BkGRAS2-GFP) 
and the control vector (35S-GFP) were introduced into onion cells by particle bombardment, with untransformed onion cells serving as a control. GFP expression was examined by fluorescence microscopy after $24 \mathrm{~h}$ of incubation. We observed signals throughout cells transformed with the control plasmid (35S-GFP, Figure 9A). In cells transformed with the 35S-BkGRAS2-GFP plasmid (Figure 9B), GFP could be detected in the nucleus and cytoplasm. Therefore, it is possible that BkGRAS2 plays an important role throughout the whole cell, in a similar manner as the SCL protein (Torres-Galea et al., 2006).

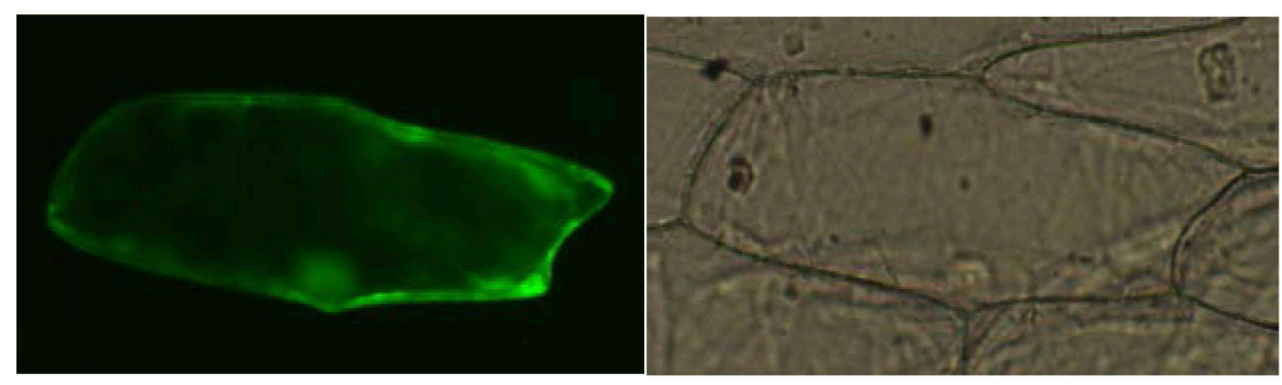

A. $35 \mathrm{~S}-\mathrm{GFP}$

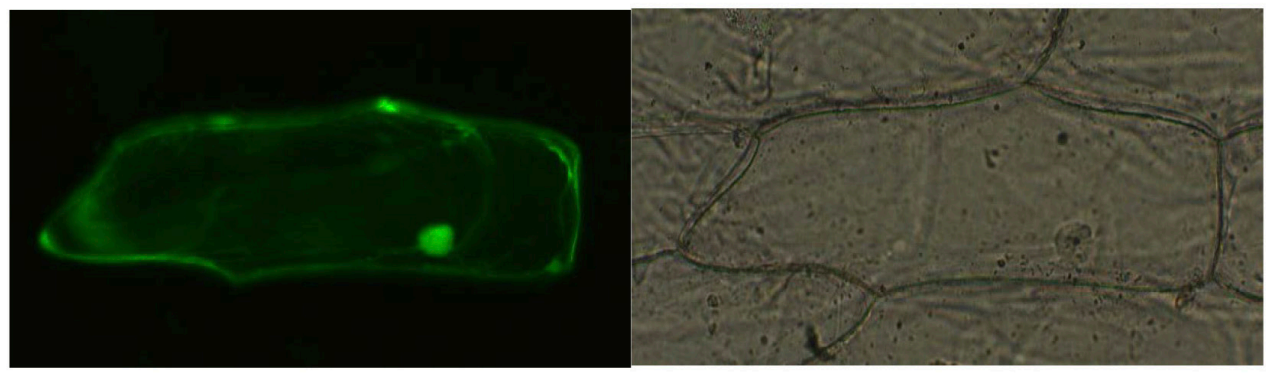

B. $35 S-B k G R A S 2-G F P$

Figure 9. Subcellular distribution of BkGRAS2 in onion epidermal cells. p35S-GFP (control) and p35S-BkGRAS2-GFP were transiently expressed in onion epidermal cells. Images were captured by fluorescence and light-field microscopy for the $p 35-G F P$ (control) plasmid (A) and the p35S-BkGRAS2-GFP plasmid (B).

\section{CONCLUSIONS}

Previous research showed that some GRAS genes respond to salt, drought, and low temperature stresses. Here, we used transcriptome sequences in databases to screen for a GRAS gene in the transcriptome of $B$. kirghisorum, and then cloned the gene and performed a bioinformatic analysis. We also examined the expression behavior of this gene under salt stress. The BkGRAS2 gene identified here showed close similarity to BkGRAS1 at the nucleotide and protein levels. Analysis of expression of BkGRAS2 showed that it was induced by a $0.6 \% \mathrm{NaHCO}_{3}$ stress, and that the relative levels of expression varied with time and among tissues. Further experiments will be necessary to elucidate the specific mechanisms of this expression pattern.

The BKGRAS2 protein did not show localization, but it was distributed throughout the cell. This suggests that BkGRAS2, possibly in combination with other genes, plays a role in the nucleus, 
and that after transfer, it also functions in the cytoplasm. The experiment provides fundamental data for the identification and analysis of members of the GRAS gene family in B. kirghisorum, and provides experimental information of value for developing more salt-tolerant varieties.

\section{Conflicts of interest}

The authors declare no conflict of interest.

\section{ACKNOWLEDGMENTS}

(\#DL12CA13).

Research supported by the Fundamental Research Funds for the Central Universities

\section{REFERENCES}

Bolle C, Koncz C and Chua NH (2000). PAT1, a new member of the GRAS family, is involved in phytochrome A signal transduction. Genes Dev. 14: 1269-1278.

Czikkel BE and Maxwell DP (2007). NtGRAS1, a novel stress-induced member of the GRAS family in tobacco, localizes to the nucleus. J. Plant Physiol. 164: 1220-1230.

Day RB, Tanabe S, Koshioka M, Mitsui T, et al. (2004). Two rice GRAS family genes responsive to $\mathrm{N}$-acetylchitooligosaccharide elicitor are induced by phytoactive gibberellins: evidence for cross-talk between elicitor and gibberellin signaling in rice cells. Plant Mol. Biol. 54: 261-272.

Foyer $\mathrm{CH}$ and Noctor G (2000). Oxygen processing in photosynthesis: regulation and signaling. New Phytol. 146: 359-388.

Gao MJ, Parkin IAP, Lydiate DJ and Hannoufa A (2004). An auxin-responsive SCARECROW-like transcriptional activator interacts with histone deacetylase. Plant Mol. Biol. 55: 417-431.

Guo HJ, Jiao YN, Di C, Yao DX, et al. (2009). Preliminary exploration of Arabidopsis GRAS family genes in response to osmotic and drought stress. Bull. Bot. 44: 290-299.

Heo JO, Chang KS, Kim IA, Lee MH, et al. (2011). Funneling of gibberellin signaling by the GRAS transcription regulator SCARECROW-LIKE 3 in the Arabidopsis root. Proc. Natl. Acad. Sci. U. S. A. 108: 2166-2171.

Ikeda A, Ueguchi-Tanaka M, Sonoda Y, Kitano H, et al. (2001). Slender rice, a constitutive gibberellin response mutant, is caused by a null mutation of the SLR1 gene, an ortholog of the height-regulating gene GAI/RGA/RHT/D8. Plant Cell 13: 999-1010.

Kim GB and Nam YW (2013). A novel GRAS protein gene MtSymSCL1 plays a role in regulating nodule number in Medicago truncatula. Plant Growth Regul. 71: 77-92.

Laurenzio LD, Wysocka-Diller J, Malamy JE, Pysh L, et al. (1996). The SCARECROW gene regulates an asymmetric cell division that is essential for generating the radial organization of the Arabidopsis root. Cell 86: 423-433.

Lee S, Cheng H, King KE, Wang W, et al. (2002). Gibberellin regulates Arabidopsis seed germination via RGL2, a GAI/RGAlike gene whose expression is upregulated following imbibition. Genes Dev. 16: 646-658.

Li XY, Qian Q, Fu ZM, Wang YH, et al. (2003). Control of tillering in rice. Nature 422: 618-621.

Lim J, Helariutta Y, Specht CD, Jung J, et al. (2000). Molecular analysis of the SCARECROW gene in Maize reveals a common basis for radial patterning in diverse meristems. Plant Cell 12: 1307-1318.

Llave C, Xie ZX, Kasschau KD and Carrington JC (2002). Cleavage of Scarecrow-like mRNA targets directed by a class of Arabidopsis miRNA. Science 297: 2053-2056.

Ma HS, Liang D, Shuai P, Xia XL, et al. (2010).The salt- and drought-inducible poplar GRAS protein SCL7 confers salt and drought tolerance in Arabidopsis thaliana. J. Exp. Bot. 61: 4011-4019.

Ma HS, Xia XL and Yin WL (2011). Cloning and analysis of SCL7 gene from Populus euphratica. J. Beijing Forest. Univ. 33: 1-10.

Pan BY, Gong WG, Zhang ZF and Liu C (2006). The classification and evaluation of soda saline soil of Daqing. J. Northeast Forest. Univ. 34: 57-59.

Peng JR and Harberd NP (1997). Gibberellin deficiency and response mutations suppress the stem elongation phenotype of phytochrome-deficient mutants of Arabidopsis. Plant Physiol. 113: 1051-1058.

Peng JR, Carol P, Richards DE, King KE, et al. (1997). The Arabidopsis GAl gene defines a signaling pathway that negatively regulates gibberellin responses. Genes Dev. 11: 3194-3205. 
Pysh LD, Wysocka-Diller JW, Camilleri C, Bouchez D, et al. (1999). The GRAS gene family in Arabidopsis: sequence characterization and basic expression analysis of the SCARECROW-LIKE genes. Plant J. 18: 111-119.

Sánchez C, Vielba JM, Ferro E, Covelo G, et al. (2007). Two SCARECROW-LIKE genes are induced in response to exogenous auxin in rooting-competent cuttings of distantly related forest species. Tree Physiol. 27: 1459-1470.

Schumacher K, Schmitt T, Rossberg M, Schmitz G, et al. (1999). The Lateral suppressor (Ls) gene of tomato encodes a new member of the VHIID protein family. Proc. Natl. Acad. Sci. U. S. A. 96: 290-295.

Silverstone AL, Mak PY, Martinez EC and Sun TP (1997). The new RGA locus encodes a negative regulator of gibberellin response in Arabidopsis thaliana. Genetics 146: 1087-1099.

Silverstone AL, Ciampaglio CN and Sun TP (1998). The Arabidopsis RGA gene encodes a transcriptional regulator repressing the gibberellin signal transduction pathway. Plant Cell 10: 155-169.

Solé A, Sánchez C, Vielba JM, Valladares S, et al. (2008). Characterization and expression of a Pinus radiata putative ortholog to the Arabidopsis SHORT- ROOT gene. Tree Physiol. 28: 1629-1639.

Stuurman J, Jaggi F and Kuhlemeier C (2002). Shoot meristem maintenance is controlled by a GRAS-gene mediated signal from differentiating cells. Genes Dev. 16: 2213-2218.

Tester M and Davenport R (2003). $\mathrm{Na}^{+}$tolerance and $\mathrm{Na}^{+}$transport in higher plants. Ann. Bot. 91: 503-527.

Tian CG, Wan P, Sun SH, Li JY, et al. (2004). Genome-wide analysis of the GRAS gene family in rice and Arabidopsis. Plant Mol. Biol. 54: 519-532.

Torres-Galea P, Huang LF, Chua NH and Bolle C (2006). The GRAS protein SCL13 is a positive regulator of phytochromedependent red light signaling, but can also modulate phytochrome A responses. Mol. Genet. Genomics 276: 13-30.

Torres-Galea P, Hirtreiter B and Bolle C (2013). Two GRAS Proteins, SCARECROW-LIKE21 and PHYTOCHROME A SIGNAL TRANSDUCTION1, function cooperatively in phytochrome A signal transduction. Plant Physiol. 161: 291-304.

Wen CK and Chang C (2002). Arabidopsis RGL1 encodes a negative regulator of gibberellin responses. Plant Cell 14: 87-100.

Wang CY, Wu ZJ, Wang RY, Zhang SJ, et al. (2001). Soda saline soil of Sanjiang plain of Heilongjiang Province. Chin. J. Soil Sci. 34: 23-26.

Yang CJ, Cui C, Xie LF, Tian YF, et al. (2013). The analysis and cloning of BkGRAS1 gene of Betula kirghisorum. Chinese Scientific Papers Online.

Zhang ZL, Ogawa M, Fleet CM, Zentella R, et al. (2011). Scarecrow-like 3 promotes gibberellin signaling by antagonizing master growth repressor DELLA in Arabidopsis. Proc. Natl. Acad. Sci. U. S. A. 108: 2160-2165.

Zhou L, Yang Z, Zhang FC and Wang Y (2013). Expression analysis and cloning of GRAS transcription factor gene from Halostachys caspica. Acta Bot. Boreali-Occidentalia Sin. 33: 1091-1097.

Zhou LJ, Zhang FC and Wang Y (2014). Transcriptional activation identification of the transcription factor HcSCL13 from Halostachys caspica and the construction of plant expression vector. Biotechnol. Bull. 5: 1-7. 